\title{
Questes
}

vestes Revue pluridisciplinaire d'études médiévales

$34 \mid 2016$

L'hiver

\section{L'hiver : éléments bibliographiques}

\section{Anne Kucab et Elodie Pinel}

\section{(2) OpenEdition}

\section{Journals}

Édition électronique

URL : http://journals.openedition.org/questes/4367

DOI : 10.4000/questes.4367

ISSN : 2109-9472

\section{Éditeur}

Les Amis de Questes

\section{Édition imprimée}

Date de publication : 15 décembre 2016

Pagination : 173-176

ISSN : 2102-7188

\section{Référence électronique}

Anne Kucab et Elodie Pinel, «L'hiver : éléments bibliographiques », Questes [En ligne], 34 | 2016, mis en ligne le 21 décembre 2016, consulté le 14 septembre 2020. URL : http://journals.openedition.org/ questes/4367 


\section{Références bibliographiques}

\section{L'hiver dans le calendrier}

COMET, Georges, «Les calendriers médiévaux illustrés, supports idéologiques complexes », Paris, Somogy, 2002.

-, «Les calendriers médiévaux, une représentation du monde », Journal des savants, 1992, vol. 1, n 1, p. 35-98.

HenISCH, Bridget Ann, The Medieval Calendar Year, University Park, Pennsylvania State University Press, 1999.

LA SOUDIERE, Martin (de), L'Hiver : à la recherche d'une morte-saison, Lyon, La Manufacture, 1987.

LE GoFf, Jacques, Les Calendriers : leurs enjeux dans l'espace et dans le temps, Paris, Somogy, 2002.

WALTER, François, Hiver : Histoire d'une saison, Paris, Payot, 2013.

\section{Hiver, climat et météorologie}

Des Climats et des hommes, dir. Claudie HaIGnere, Jean-Paul JACOB, François JACQ, Yves CopPEns, Paris, la Découverte, 2012.

La Pluie, le soleil et le vent : une histoire de la sensibilité au temps qu'il fait, dir. Alain CORBIN, Paris, Aubier, 2013.

Sunspot Cycles, dir. Derek Justin Schove, Stroudsburg, Hutchinson Ross Publishing, 1983.

AleXANDre, Pierre, Le Climat en Europe au Moyen Âge : contribution à l'histoire des variations climatiques de 1000 à 1425, d'après les sources narratives de l'Europe occidentale, Paris, Éditions de l'École des hautes études en sciences sociales, 1987.

LAMB, Hubert Horace, The Changing Climate, London, Methuen, 1966.

LE Roy Ladurie, Emmanuel, Histoire du climat depuis l'an mil, Paris, Flammarion, 2009 [1967].

-, Histoire humaine et comparée du climat, Paris, Fayard, 2004.

LITZENBURGER, Laurent et LE ROY LADURIE, Emmanuel, Une Ville face au climat: Metz à la fin du Moyen Âge 1400-1530, Nancy, PUN-Éditions universitaires de Lorraine, 2015.

SARRAMEA, Jean, 1407-1408: a Severe winter at the end of the Middle Ages dans Western Europe, http://hdl.handle.net/2042/47083 [consulté le 5 décembre 2015]

Thiebault, Stéphanie, «2. L'homme et le climat : l'apport de l'archéologie environnementale », Hors collection Sciences Humaines, 2008, p. 26-39. 


\section{Hiver et alimentation}

DAuBy, Hélène, «Les saisons et les mets à la fin du Moyen Âge, en Angleterre et en France », dans La Ronde des saisons. Les Saisons dans la littérature et la société anglaises au Moyen Âge, 1998, p. 101-109.

GAUTIER, Alban, Du Hareng pour les princes, du hareng pour les pauvres : IX $X^{e}$ XIII siècles, Strasbourg, Université Marc Bloch, Département d'études néerlandaises, 2007.

HoCQueT, Jean-Claude, " Métrologie de la pêche. Les poissons du Nord, hareng et morue ", dans Diversité régionale et locale des poids et mesures dans l'ancienne France, 1996, p. 177-188.

Pastoureau, Michel, Le Cochon : histoire d'un cousin mal aimé, Paris, Gallimard, 2009.

Rouche, Michel, «Les repas de fête à l'époque carolingienne » dans Manger et Boire au Moyen Âge, Actes du Colloque de Nice (1982), dir. Denis Menjot, Paris, Les Belles Lettres, 1984, p. 265-296.

\section{Jeux et fêtes hivernales}

Crèches et traditions de Noël, Paris, RMN, 1986.

La Nativité et le temps de Noël : Antiquité et Moyen Âge, dir. Jean-Paul BOYER, Gilles DORIVAL, Aix-en-Provence, Publications de l'Université de Provence, 2003.

AlEXANDRE-BIDON, Danièle, «Folklore, fêtes et traditions populaires de Noël et du premier de l'an (XIV ${ }^{e}-X V I^{e}$ siècles) », Razo, vol. 8, 1988, p. 37-64.

-, «Les jeux et sports d'hiver au Moyen Âge et à la Renaissance », dans Jeux, sports et divertissements au Moyen Âge et à l'Âge classique. Actes du $116^{e}$ Congrès national des Sociétés savantes (Chambéry, 1991), Section d'Histoire médiévale et de philologie, édition du C.T.H.S., 1993, p. 143-156.

Cropp, Glynnis M., «Les Douze mois figuréz, un manuscrit et une traduction » dans Romania, t. CI, 1980, p. 262-271.

FERY, Robert, Jours de fêtes : histoire des célébrations chrétiennes, Paris, Seuil, 2008.

JudDe De LARIVIERE, Claire, La Révolte des boules de neige : Murano face à Venise, 1511, Paris, Fayard, 2014.

LeVI-STRAuss, Claude, «Le Père Noël supplicié », Temps Modernes, vol. 77, p. $1572-1590$.

PoulaiLle, Henry, La Grande et Belle Bible des Noëls anciens, du XII ${ }^{e}$ au XVI ${ }^{e}$ siècles, Paris, Albin Michel, 1942.

VAULTIER, Roger, Le Folklore pendant la Guerre de Cent Ans d'après les lettres de Rémission du Trésor des Chartes, Guénégaud, 1965. 


\section{Hiver et littérature}

La Ronde des saisons, dir. Leo Martin CARruthers, Paris, Presses de l'Université de Paris-Sorbonne, 1998.

ENKVIST, Nils Erik, The Seasons of the year, chapters on a motif from Beowulf to the Sheperd's Calendar, Helsingfors, Societas Scientiarum Fennica, 1957.

HüE, Denis, «L'hiver du Moyen Âge » dans Hommage à Jean-Charles Payen. Farai chansoneta novele. Essais sur la liberté créatrice au Moyen Âge, Caen, Centre de Publications de l'Université de Caen, 1989.

HuIZINGA, Johan, L'Automne du Moyen Âge, Paris, Payot, [1995] 2002.

LeMAIRE, Jacques-Charles, Un Poème inédit sur les saisons : "l'histoire d'ivier et de prinztampz » (Ms. Bruxelles, B.R., IV 541), Bruxelles, Archives et Bibliothèques de Belgique, 2009.

LUCKEN, Christopher, «Dans l'hiver de la lecture. Le temps de la fable », Littérature, 2007, vol. 148, n 4, p. 98-120.

ORUCH, Jack B., «St. Valentine, Chaucer, and Spring in February », Speculum, vol. LVI, n 3 , juillet 1981, p. 534-565.

MEnARD, Philippe, "Sur Noël, morte saison, / Que les loups se vivent de vent", Tradition littéraire et folklore chez Villon (Lais, 10-11) » dans Études de Philologie Romane et d'Histoire Littéraire offertes à Jules Horrent, Liège, D'Heur, 1980, p. 309-315.

PeARSAll, Derek et SALTER, Elizabeth, Landscapes and seasons of the medieval world, Londres, Paul Elek, 1973.

TUVE, Rosemond, Seasons and months. Studies in a tradition of middle english poetry, Paris, Librairie universitaire S.A., 1993.

VIGneron, Fleur, Les Saisons dans la poésie française des XIV et XV siècles, Paris, Champion, 2002.

Wilhelm, James J., The Cruelest Month. Spring, nature, and love in classical and medieval lyrics, New Have/Londres, Yale University Press, 1965.

\section{Représenter l'hiver}

Briantais-RouYer, Helga, Deslandes, Yohann, Dugue, François, Images de Noël au Moyen Âge, Musée départemental des antiquités, Rouen, Rouen, Musée départemental des antiquités Conseil général de la Seine-Maritime, 2003.

Metzger, Alexis et StaSzaK, Jean-François, Plaisirs de glace : essai sur la peinture hollandaise hivernale du Siècle d'or, Paris, Hermann, 2012. 


\section{L'hiver dans les textes scientifiques}

Ducos, Joëlle et Thomasset, Claude, Le Temps qu'il fait au Moyen Âge : phénomènes atmosphériques dans la littérature, la pensée scientifique et religieuse, Paris, Presses de l’Université de Paris-Sorbonne, 1998.

Grant, Edward, La Physique au Moyen Âge (VI $-X V^{e}$ siècle), Paris, PUF, 1995. 